\title{
Pathological mimics of chronic inflammatory bowel disease
}

\author{
N A Shepherd
}

\section{Introduction}

Ulcerative colitis, Crohn's disease, and their intermediate forms collectively referred to as idiopathic chronic inflammatory bowel disease, show a spectrum of pathological changes. Essentially their pathological diagnosis is one of exclusion of the many causes of inflammation in the intestines. The ultimate diagnosis may require corroboration with clinical, microbiological, and radiological data. With the advent of fibreoptic endoscopy, pathologists are more often confronted with mucosal biopsy specimens of the gastrointestinal tract, and the success of newer surgical techniques has meant that pathologists are increasingly pressured to make unequivocal diagnoses of ulcerative colitis and Crohn's disease. For instance, many would now consider restorative proctocolectomy with ileal reservoir to be the operation of choice in ulcerative colitis when medication has failed to control the disease, ${ }^{1}$ and yet Crohn's disease is an absolute contraindication for this operation. ${ }^{2}$ It is essential, therefore, that the correct diagnosis is made before surgery is contemplated.

The importance of macroscopic examination of surgical specimens to differentiate ulcerative colitis and Crohn's disease has been emphasised, but the pathologist more often has to make important diagnostic decisions, which will directly affect patient management, on biopsy specimens. Although both ulcerative colitis and Crohn's disease show characteristic histological features in their classic form, none of the morphological changes seen in either condition is entirely specific. Pathologists generally rely on a combination of morphological features to make the appropriate diagnosis. This is especially so in Crohn's disease in which pathological features vary greatly from case to case. The two most characteristic features, fissuring ulceration and granulomas, can be seen in many other conditions. Transmural inflammation is a little more specific but this feature is also seen in several other conditions. In about $10 \%$ of cases, particularly in acute fulminant colitis, it may be impossible to differentiate the conditions and the term "indeterminate colitis" is used. ${ }^{3}$ For the purposes of this review it is not intended to concentrate on the pathological differentiation of ulcerative colitis and Crohn's disease as this has been the subject of standard texts and reviews. ${ }^{4-6}$ This review is primarily concerned with recently described conditions and newly recognised situations where the microscopic features may inappropriately suggest a diagnosis of chronic inflammatory bowel disease.

\section{Iatrogenic inflammatory bowel disease}

Various therapeutic manoeuvres, both surgical and medical, may directly cause inflammatory pathology in the intestines. Certain surgical procedures can result in morphological changes which simulate chronic inflammatory bowel disease: these changes are largely independent of the original indication for surgery and represent a tissue response to an altered environment. Drugs can cause inflammation of the intestinal mucosa. In the small bowel enteric coated preparations and non-steroidal anti-inflammatory drugs are common causes of inflammation, while in the large intestine mucosal inflammatory changes are seen particularly with anti-neoplastic agents and after enemas and suppositories.

\section{DIVERSION COLITIS AND THE DEFUNCTIONED RECTUM}

When part of the colon or rectum is excluded from the faecal stream for any reason, the colorectal mucosa may become inflamed. The pathogenesis of this diversion colitis probably relates to the lack of essential short-chain fatty acids, particularly butyrates, normally produced by anaerobic bacteria, which maintain the healthy colonic mucosa. ${ }^{78}$ Such diversion colitis or proctitis occurs in the defunctioned large intestine in patients with functional disorders, diverticular disease, and colorectal cancer. ${ }^{910}$ Macroscopically, the condition is said to resemble ulcerative colitis. ${ }^{1112}$ Histologically, diversion colitis shows diffuse chronic inflammation of the lamina propria and crypt abscesses may be present: in general the lack of gross crypt architectural distortion and goblet cell depletion militates against a diagnosis of ulcerative colitis (fig 1). ${ }^{13}$ In severe cases, however, diversion colitis may closely simulate ulcerative colitis microscopically. ${ }^{914}$ Furthermore, the presence of mucosal granulomas, together with the inflammatory pathology, may create a histological appearance reminiscent of Crohn's disease. ${ }^{14} 15$ The picture is further complicated by the fact that ulcerative colitis and Crohn's disease are both common indications for faecal stream diversion. In ulcerative colitis the rectum is often defunctioned as a mucus fistula after total colectomy, and severe colonic Crohn's disease may be ameliorated by faecal stream diversion. ${ }^{1617}$ The defunctioned rectum in patients with ulcerative colitis may show transmural inflammation, fissures, and granulomas: an erroneous diagnosis of Crohn's disease may result. ${ }^{18}$ It should be emphasised that the pathological examination of a defunctioned segment of bowel may be very misleading: the diagnosis of chronic inflammatory 


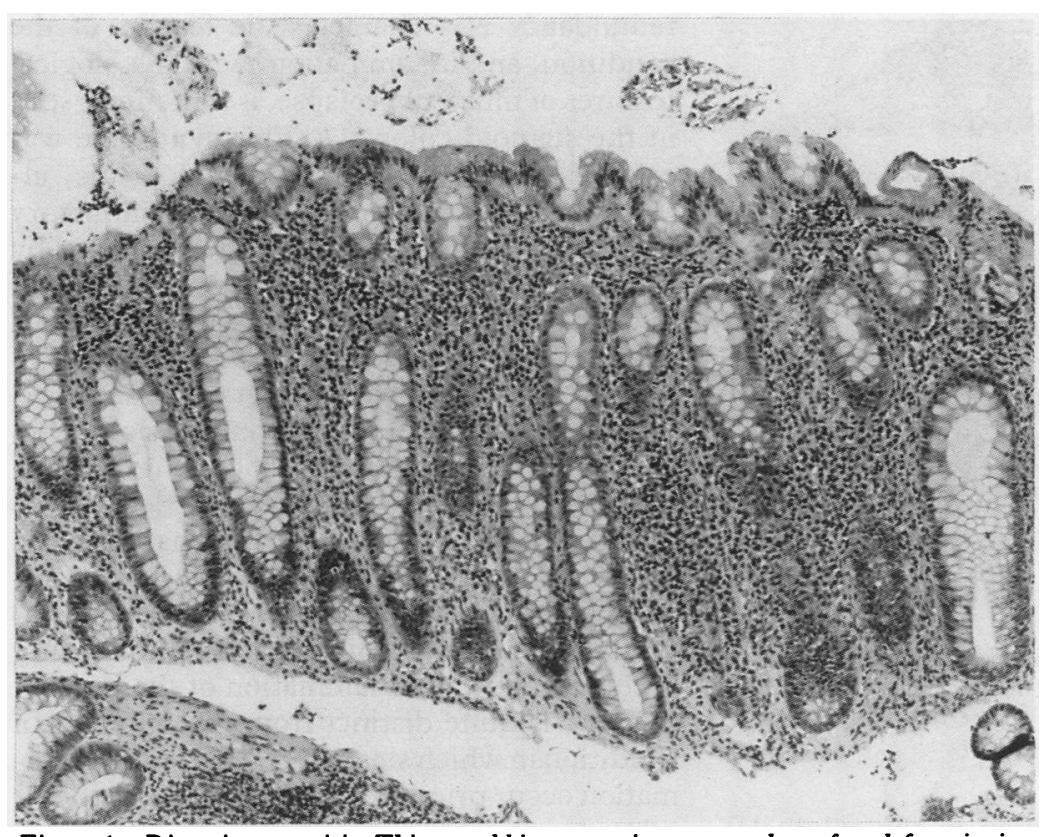

Figure 1 Diversion proctitis. This rectal biopsy specimen was taken after defunctioning of the rectum following a vesicocolic fistula complicating diverticular disease. There is diffuse chronic inflammation of the lamina propria in the absence of gross crypt distortion. Active inflammation with crypt abscesses was also present (haematoxylin and eosin).
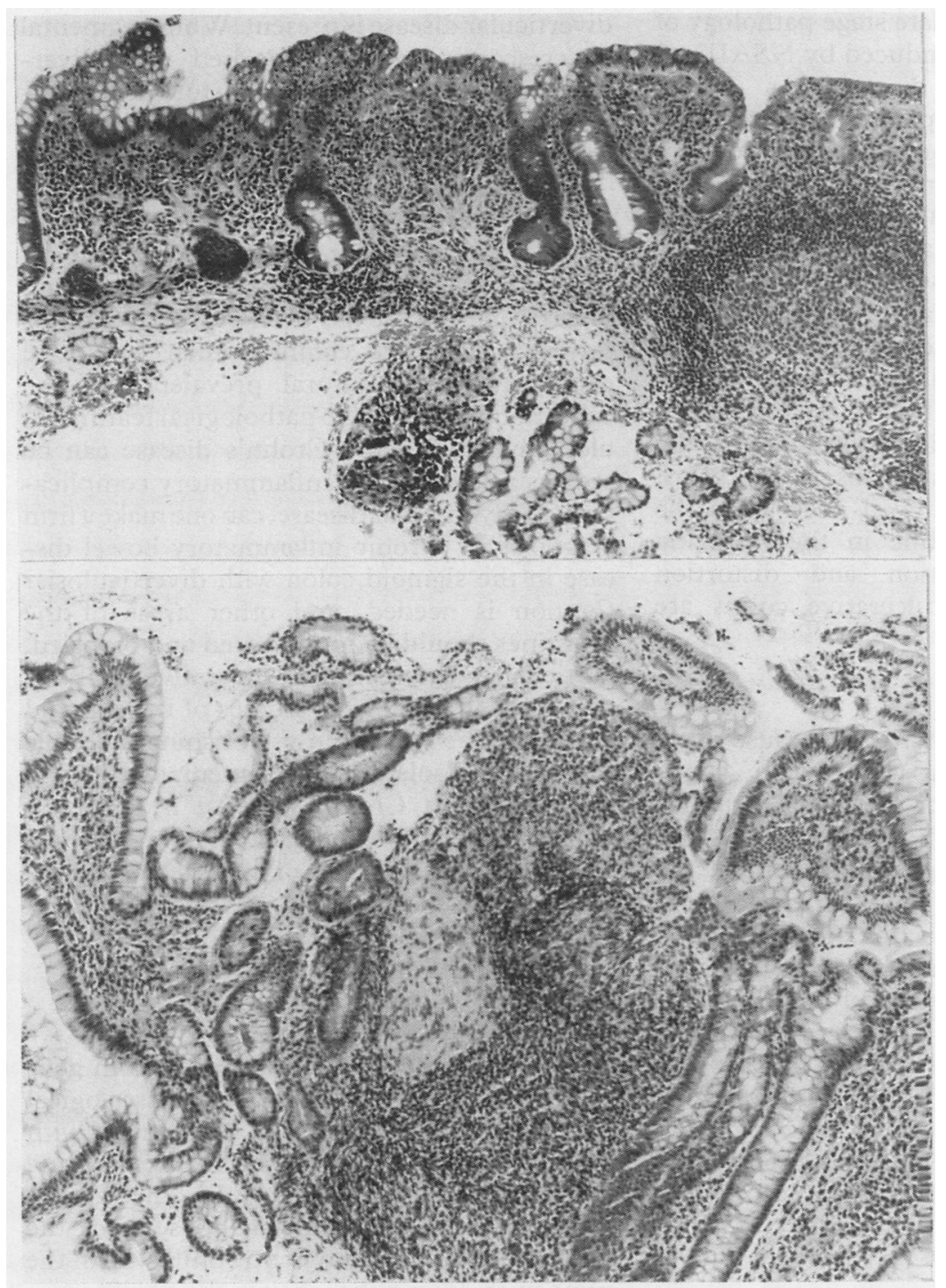

Figure 2 Mucosal biopsy specimens from pelvic ileal reservoirs. (A) There is subtotal villous atrophy, diffuse chronic injtammation, and gross crypt distortion. (B) $A$ well circumscribed epithelioid granuloma in the characteristic position within a lymphoid follicle in a rather distorted mucosal biopsy specimen. In the absence of other stigmata of Crohn's disease such granulomas probably represent a tissue reaction to persorbed intraluminal material (haematoxylin and eosin). bowel disease should be restricted to the examination of colon excised before faecal stream diversion. ${ }^{18}$

THE ILEAL RESERVOIR

Restorative proctocolectomy with ileal reservoir is now one of the more favoured surgical alternatives among both surgeons and patients, for patients with ulcerative colitis requiring total colectomy, and for those with familial adenomatous polyposis. ${ }^{1920}$ The creation of an ileal reservoir, both pelvic as in restorative proctocolectomy, or abdominal as in Kock's continent ileostomy, is complicated by inflammatory changes with varying degrees of villous atrophy in the ileal mucosa. ${ }^{22}$ The villous atrophy and crypt hyperplasia produce a morphological appearance of colonic metaplasia. In those cases with extensive acute and chronic inflammation, particularly those patients with the chronic relapsing inflammatory condition known as pouchitis, the mucosa shows a close resemblance to the colorectal mucosa in ulcerative colitis (fig 2A). Both clinically and pathologically there are close links between pouchitis and ulcerative colitis; it may be that pouchitis and ulcerative colitis share immunopathogenetic mechanisms ${ }^{23}$ or that pouchitis represents a form of ulcerative colitis in metaplastic ileal mucosa. ${ }^{24}$

It has been suggested that Crohn's disease may develop in the reservoir after proctocolectomy for indisputable ulcerative colitis $^{25}$ and even that pouchitis may be a manifestation of Crohn's disease. The pathological hallmarks of Crohn's disease, however, namely granulomas, transmural inflammation and fissures, may all be seen as a consequence of surgical manipulation and reservoir construction. ${ }^{26}$ As in many other sites in the gut, granulomas are a major source of diagnostic confusion. They are occasionally seen, particularly in lymphoid follicles, in the reservoir mucosa of patients with an indisputable diagnosis of ulcerative colitis (fig 2B). ${ }^{26}$ Such granulomas probably represent a reaction of the ileal mucosa, particularly the lymphoid tissue, to an altered intraluminal environment or to extraneous material. Crohn's disease remains an absolute contraindication for pelvic reservoir surgery ${ }^{2}$ : pathological changes within the reservoir may closely resemble those seen in Crohn's disease but such a diagnosis should not be made solely on the pathological changes seen in the reservoir.

\section{DRUGS}

Small bowel ulceration may be caused by any number of conditions, although drugs seem to be a common cause. ${ }^{27}$ Enteric coated potassium supplements cause small bowel ulceration, probably by an ischaemic effect due to vascular constriction induced by high concentrations of potassium ions: the histological changes affect only the mucosa and submucosa and are unlikely to be confused with active Crohn's disease. ${ }^{28}$ Now accepted as one of the commonest causes of clinically important ileal ulceration are non-steroidal anti-inflammatory drugs (NSAIDs). ${ }^{29}$ These also cause mucosal 


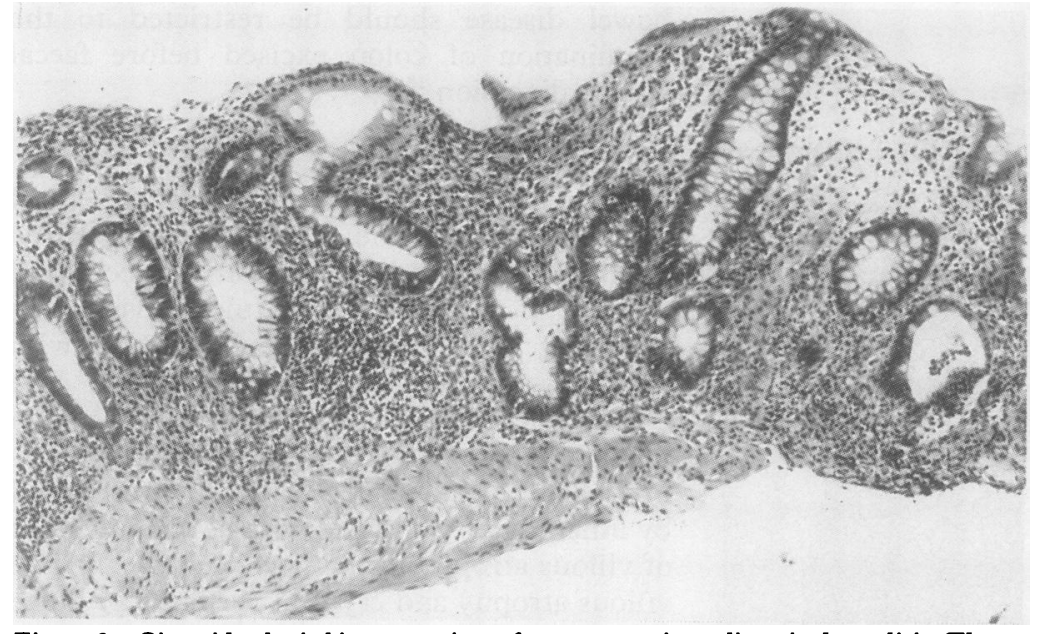

Figure 3 Sigmoid colonic biopsy specimen from crescentic or diverticular colitis. There is diffuse chronic inflammation with pronounced crypt distortion and crypt abscesses are present (right). There was no clinical or radiological evidence of ulcerative colitis and the rectal mucosa was histologically normal (haematoxylin and eosin).

inflammation and ulceration in the colorectal mucosa. ${ }^{30}$ The picture is complicated by the fact that NSAIDs may exacerbate chronic inflammatory bowel disease. ${ }^{31} 32$ Attention has recently focused on the late stage pathology of small intestinal disease induced by NSAIDs. ${ }^{29}$ So-called diaphragm disease has highly characteristic macroscopic and microscopic appearances, which, once recognised, are readily differentiated from Crohn's disease. ${ }^{29}$

NSAIDs, methyldopa, gold, antineoplastic agents and penicillins are the most widely recognised drugs known to cause active inflammation in the large intestinal mucosa. Methyldopa causes an acute colitis in a small proportion of cases ${ }^{33}$ and gold causes a characteristic eosinophilic infiltrate. ${ }^{34} 5^{\prime}$ fluoro-uracil has been the most widely studied of the chemotherapeutic agents to cause acute colitis. In the acute phase epithelial necrosis is the predominant feature while in the resolving phase crypt regeneration and distortion reminiscent of healed ulcerative colitis are observed. ${ }^{35}$

\section{ENEMAS AND SUPPOSITORIES}

Most enemas and suppositories cause little mucosal pathology but hypertonic saline enemas and bisacodyl, in particular, produce crypt epithelial proliferation and degeneration with inflammatory change. ${ }^{3637}$ In general the pathological changes due to enemas more closely resemble ischaemia or infective colitis and lack the chronic inflammatory component of chronic inflammatory bowel disease. Suppositories, particularly those containing NSAIDs, may also cause mucosal damage and result in rectal bleeding. ${ }^{38}$ The resulting histological changes are generally those of mild, non-specific chronic inflammation, but occasionally active inflammation is seen. ${ }^{38}$

\section{Diverticular disease}

Although diverticular disease is essentially a functional disorder of the colon, a wide variety of inflammatory pathology may be associated with the condition. For instance, mucosal redundancy is a characteristic feature of the condition, and inflammation, with histological features of mucosal prolapse, is sometimes seen in the sigmoid colon. ${ }^{39-41}$ This syndrome was originally described as segmental colitis, although it has become clear that inflammatory pathology restricted to the segment affected by diverticular disease shows a wide spectrum of microscopic disease, from non-specific inflammatory changes through to florid active inflammatory change associated with crypt architectural distortion simulating ulcerative colitis (fig 3). ${ }^{412}$ In a small proportion of cases it has been suggested that such segmental or crescentic colitis, the latter named for the characteristic involvement of the mucosal folds in the sigmoid, may precede the development of distal ulcerative colitis. ${ }^{41}$ This form of colitis, being predominantly an inflammation of the luminal mucosa, is quite distinct from diverticulitis, a condition in which stasis, infection, and inflammation occur primarily in the diverticula themselves. $^{43}$

The clinical and histological diagnosis of chronic inflammatory bowel disease restricted to the sigmoid colon can be very difficult when diverticular disease is present. While segmental or crescentic colitis, associated with diverticular disease, can produce histological changes that closely mimic ulcerative colitis, the three pathological hallmarks of Crohn's disease -granulomas, transmural inflammation, and fissuring ulceration-may all be seen as a result of diverticular disease of the sigmoid colon. ${ }^{41}$ An association between Crohn's disease and diverticular disease has been postulated, but is probably no more common than would be expected by the natural prevalence of the conditions. ${ }^{44}{ }^{45}$ If all the pathological features of ulcerative colitis and Crohn's disease can be seen as a result of the inflammatory complications of diverticular disease, can one make a firm diagnosis of chronic inflammatory bowel disease in the sigmoid colon with diverticulosis? Caution is needed, and other areas of the intestines should be investigated and biopsied, particularly the rectum if ulcerative colitis is suspected. Radiological studies of the sigmoid colon may be helpful in establishing a double diagnosis. ${ }^{46}$ Isolated involvement of the sigmoid colon in Crohn's disease is relatively unusual and doubt should be cast on any such diagnosis in the presence of diverticular disease and the absence of any other stigmata of Crohn's disease.

\section{Infective enterocolitis}

Infectious (acute, self-limiting) colitis in general has rather characteristic histological features which are unlikely to be confused with ulcerative colitis. The predominance of acute over chronic inflammatory cells, the lack of crypt architectural abnormalities, and the presence of oedema and neutrophils within the crypt epithelium rather than in the crypt lumen are all helpful features in favour of infective colitis. ${ }^{478}$ Occasionally, ulcerative colitis-like changes may be seen in more chronic forms of infectious colitis, particularly chronic 
Figure 4

Microgranulomas (arrowheads) in resolving phase of culture confirmed salmonella enterocolitis (haematoxylin and eosin).

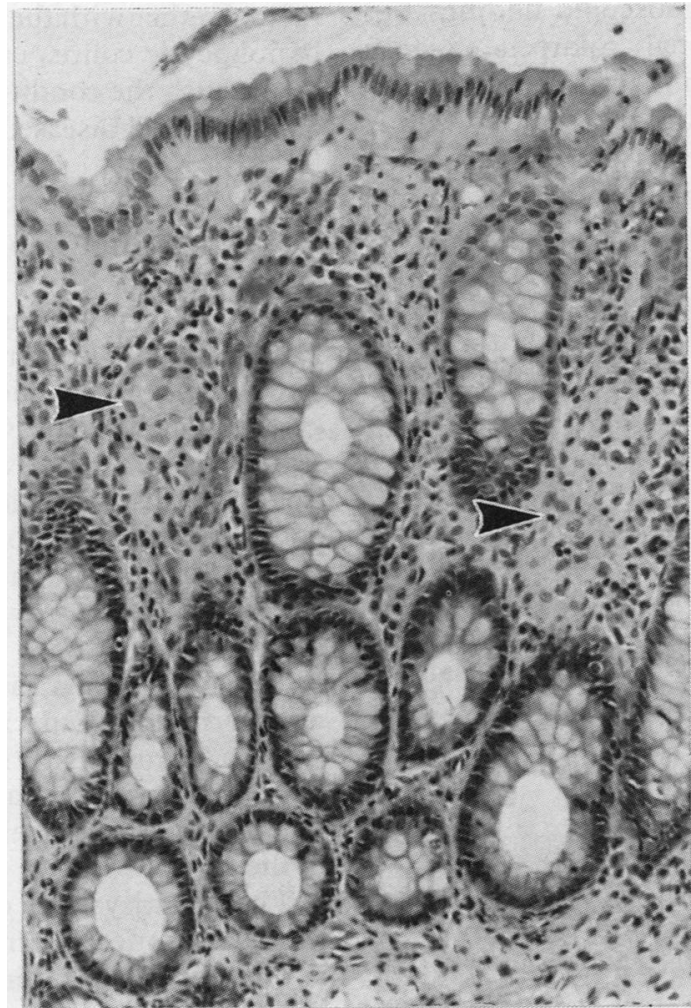

shigellosis and amoebiasis. ${ }^{49}$ Acute chlamydial proctitis may resemble active ulcerative colitis. ${ }^{50}$ These ulcerative colitis-like changes occur more often with the bacteria that cause inflammation by direct invasion of the mucous membrane as opposed to those which elaborate a toxin such as Salmonella and Yersinia. ${ }^{51}$ It may be difficult to differentiate infectious colitis, particularly in a resolving phase, from Crohn's disease in colonic biopsy specimens. ${ }^{6}$ Poorly circumscribed microgranulomas are a feature of some infective colitides, particularly salmonella ${ }^{52}$ (fig 4) and Campylobacter..$^{53}$ Microbiology is not always helpful-in only about $40 \%$ of cases is an infectious agent identified. ${ }^{48}$ Most

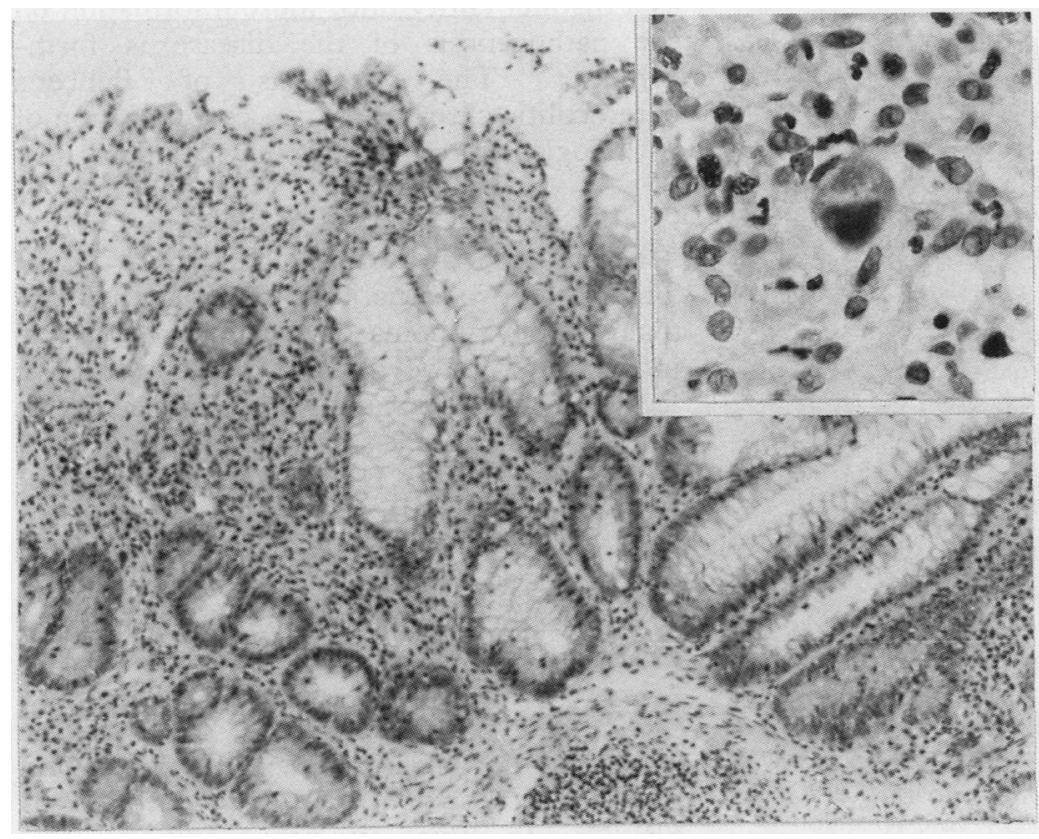

Figure 5 CMV colitis. The inflammatory changes with crypt architectural abnormalities resemble ulcerative colitis. Inset: CMV inclusions are present (haematoxylin and eosin). helpful histological variables are evidence of inflammatory and architectural chronicity and the presence of well formed epithelioid granulomas, these changes favouring a diagnosis of Crohn's disease. Pseudomembranous enterocolitis, due to Clostridium difficile toxin, is most likely to be mistaken for acute ischaemia rather than chronic inflammatory bowel disease, although early lesions show non-specific patchy inflammation with surface epithelial degeneration. ${ }^{54}$

Well formed granulomas are a feature of some infective colitides, chlamydial infection, ${ }^{55}$ yersiniosis, ${ }^{56} 57$ and tuberculosis being the most characteristic. Yersiniosis is perhaps the most likely infectious enterocolitis to produce pathological confusion with Crohn's disease. The most helpful differentiating features are central necrosis within granulomas and the relative lack of transmural inflammation in yersiniosis. ${ }^{57}$ Examination of local lymph nodes, if available, is also helpful. ${ }^{58}$ If there is any doubt yersinia serology should be performed. In cases of Crohn's disease associated with a florid sarcoid-like granulomatous response it may be impossible to rule out tuberculosis on histological grounds alone. Tuberculosis is favoured if there is florid coalescent granulomatous inflammation, extensive caseous necrosis (some central necrosis is seen in Crohn's granulomas, particularly in the anal region), and nodal granulomas in the absence of intramural granulomas. ${ }^{5960}$ Acid fast bacilli are only demonstrable in about $50 \%$ of intestinal tuberculosis cases but clinical data, including chest radiology and Mantoux testing, may be of value. ${ }^{61}$ Other infective granulomatous conditions, such as schistosomiasis, deep mycoses, and larval infestations are not often confused with Crohn's disease as the infecting organisms are usually readily identifiable.

Viral infection, in particular by cytomegalovirus (CMV) and herpes simplex virus (HSV), may result in acute enterocolitis, especially in the immunosuppressed. Both produce characteristic histological appearances reminiscent of chronic inflammatory bowel disease (fig 5): the clinical history and the presence of inclusion bodies and multinucleate giant cells help to substantiate the diagnosis of viral enterocolitis. CMV colitis is a recognised complication of ulcerative colitis and may induce acute fulminant colitis with toxic dilatation. ${ }^{62}$ $\mathrm{CMV}, \mathrm{HSV}$, and cryptosporidiosis may produce a florid active enterocolitis, masquerading as active ulcerative colitis, in patients with AIDS. The correct diagnosis relies on the demonstration of the organisms or their cytopathic effects. The enterocolitis of atypical myobacteriosis in AIDS is not usually confused with Crohn's disease as the histiocytic infiltrate diffusely involves the lamina propria and Ziehl-Neelsen stains show overwhelming numbers of bacteria.

\section{Non-specific (microscopic) colitis and lymphocytic colitis}

Microscopic colitis denotes a patient group with chronic watery diarrhoea and normal 
radiological and sigmoidoscopic findings but microscopically abnormal colorectal biopsy specimens. ${ }^{6364}$ The term is ambiguous as other conditions, including both ulcerative colitis and Crohn's disease, may show histopathological abnormalities in the face of normal macroscopic appearances. ${ }^{6566}$ A characteristic pathological feature of the disease is surface epithelial degeneration with a noticeably increased intraepitheliallymphocyte infiltrate, ${ }^{67}$ and it has been proposed that the condition be renamed lymphocytic colitis. ${ }^{6768}$ Histologically, lymphocytic colitis shares some of the features of collagenous colitis, but these colitides can be differentiated on examination of the biopsy specimen. ${ }^{67}$ The chronic inflammatory changes that occur in lymphocytic (microscopic) colitis may suggest a diagnosis of chronic inflammatory bowel disease: the lack of crypt architectural distortion and active cryp-

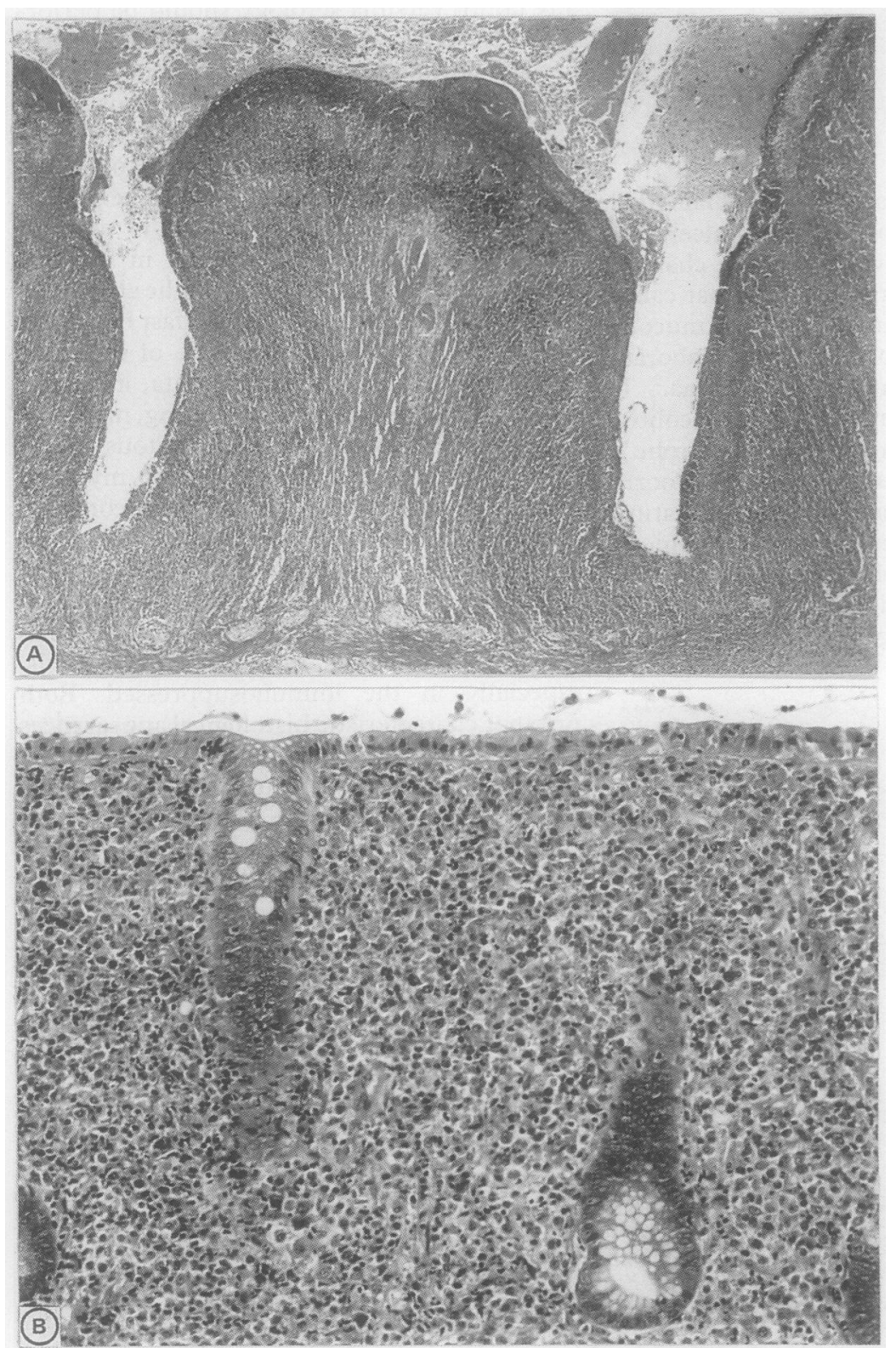

Figure 6 Primary malignant lymphoma of the intestines. $(A)$ deep destructive fissuring ulceration in a small intestinal lymphoma. At this magnification the lymphomatous infiltrate is not obvious and the pathology could easily be mistaken for Crohn's disease. (B) diffuse intramucosal lymphoma of the colon mimicking chronic inflammatory bowel disease (haematoxylin and eosin). titis, together with the characteristic changes of lymphocytic colitis, enables the pathologist to distinguish the condition from chronic inflammatory bowel disease. ${ }^{67}$

\section{Ischaemic enterocolitis and Behçet's syndrome}

Acute forms of ischaemic enterocolitis present little differential diagnostic dilemma. Chronic strictures in ischaemic enterocolitis may suggest a diagnosis of Crohn's disease. Histologically, the reparative and chronic phases of ischaemia disclose microscopic fissures, crypt epithelial regeneration and distortion, and chronic inflammation, features suggestive of chronic inflammatory bowel disease. Helpful microscopic features for establishing a diagnosis of ischaemia are the presence of haemosiderin laden macrophages in the lamina propria, fibrosis of the lamina propria, a relative paucity of chronic inflammatory cells and selective damage to the more superficial epithelium of the crypt. ${ }^{6970}$

The multisystem disorder Behçet's syndrome may affect the intestines: colonic disease is sometimes a prominent feature of the syndrome. ${ }^{71}$ Ulceration is the most characteristic feature, either localised to the ileo-caecal region or more diffusely affecting the colon. ${ }^{72}$ Colitis in Behçet's syndrome shows typical aphthoid ulcers and mucosal cobblestoning; granulomas may be present. ${ }^{72}{ }^{73}$ Vasculitis is often seen in Behçet's colitis, affecting small veins and venules. $^{74}$ Controversy still abounds about the enterocolitis of Behçet's syndrome: it has been intimated that it is not a specific entity but rather a variant of chronic inflammatory bowel disease. ${ }^{67172}$ Although many of the pathological features are similar to those in Crohn's colitis, Behçet's syndrome is said to lack the aggregated lymphocytic transmural inflammation of Crohn's disease. ${ }^{75}$ Current opinion is that Behçet's enterocolitis should be regarded as a distinct entity until more information on the pathogenesis of the disease is forthcoming. ${ }^{75}$ The diagnosis of Behçet's enterocolitis clearly relies on corroboration of pathological findings with clinical data.

\section{Malignant lymphoma}

There are two situations in which primary malignant lymphoma of the gut may mimic inflammatory bowel disease. Deep, destructive fissuring ulceration is a highly characteristic feature of high grade small and large intestinal lymphomas of both $B$ and $T$ cell phenotype ${ }^{76}$ (fig 6A) and this may mimic Crohn's disease, particularly in those tumours with relatively few neoplastic cells and innumerable eosinophils. ${ }^{77}$ In the large bowel diffuse lymphoma is relatively unusual but may be seen in both primary and secondary disease. ${ }^{78}$ Occasionally the disease is predominantly mucosal and shows similar macroscopic and histological changes to those of acute ulcerative colitis (fig $6 \mathrm{~B}){ }^{79-81}$ In this situation immunohistochemistry may help to differentiate the conditions. ${ }^{81}$ Very occasionally ulcerative colitis and 


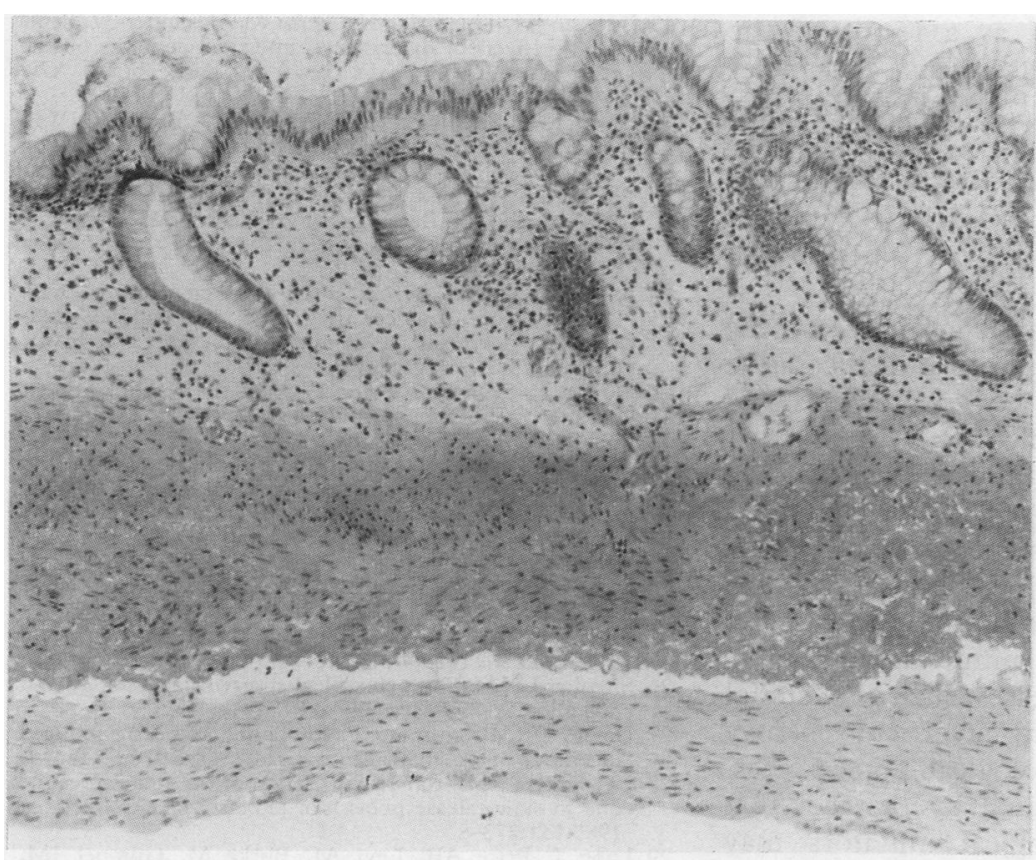

Figure 7 Pneumatosis cystoides intestinalis. The mucosa shows gross crypt atrophy and distortion and the muscularis mucosae is thickened. Close inspection of the lower edge of the biopsy specimen shows the histiocytic lining of a submucosal gas cyst. Intramucosal granulomas were also present (haematoxylin and eosin).

malignant lymphoma may coexist: primary malignant lymphoma of the large bowel is a rare but well recognised complication of chronic ulcerative colitis. ${ }^{82}$

\section{Miscellaneous \\ IMMUNE DEFICIENCY SYNDROMES}

It is the acquired immunodeficiency syndromes that are most often confused histologically with chronic inflammatory bowel disease. Graftversus-host disease (GvHD) in the acute phase shows crypt distortion and degeneration with crypt abscesses ${ }^{83}$ : as the disease progresses there is gross crypt atrophy.$^{84}$ The absence of a predominant inflammatory component and the presence of the "exploding crypt lesion", in which individual cell necrosis can be shown histologically and ultrastructurally in the crypt epithelium, are helpful in distinguishing GvHD from chronic ulcerative colitis. ${ }^{85}$ Although clinically important intestinal pathology is caused by specific infection in patients with AIDS, AIDS is also complicated by a non-specific enterocolitis. ${ }^{86}$ This is the result of immunologically mediated damage to the intestinal epithelium similar to that seen in GvHD, with similar histological appearances. ${ }^{87}$ In the absence of other histological clues the diagnosis may be reached by confirming the presence of HIV in rectal crypt epithelium by in situ hybridisation. ${ }^{88}$

The autosomal recessive disorder chronic granulomatous disease of childhood (CGD) is complicated by a colitis with similarities to Crohn's disease. ${ }^{89}$ The conditions may be differentiated by the presence of a histiocytic infiltrate containing lipid vacuoles and pigment histochemically similar to lipofuscin in $\mathrm{CGD}^{90}$ and by the normal leucocyte bactericidal activity in Crohn's disease. ${ }^{91}$ Inherited immune deficiency syndromes cause malabsorption, probably as a result of chronic enteric infection, particularly giardiasis, with histological features like those of coeliac disease, ${ }^{92}$ and occasionally they cause nodular lymphoid hyperplasia particularly in the ileum ${ }^{93}$ : inflammatory pathology similar to chronic inflammatory bowel disease is generally not encountered.

\section{NEUROMUSCULAR AND VASCULAR CHANGES IN THE} INTESTINES

The lesions of Crohn's disease may undergo spontaneous healing. ${ }^{94}$ In these cases a confusing histological picture is produced with hyalinised granulomas and little or no inflammation. The most striking findings are often seen in the connective tissues. Neuronal hyperplasia, both of ganglion cells ${ }^{95}$ and nerve trunks, ${ }^{96}$ may mimic diffuse neurofibroma or intestinal ganglioneuromatosis, ${ }^{97}$ while the vascular degenerative changes may suggest a primary vasculitis. Another striking feature of late stage Crohn's disease is the muscularisation of the fibrotic submucosa, a feature also seen in ischaemic and radiation enterocolitis. ${ }^{98}$ The late stage of any localised intestinal ulcer could be misinterpreted as Crohn's disease. In these cases the presence of fissuring ulceration, granulomas, or active inflammation elsewhere are features which can be used toward a diagnosis of Crohn's disease.

\section{EOSINOPHILIC INFILTRATES OF THE GUT}

Several heterogeneous conditions may cause a tissue eosinophilia in the intestines ${ }^{99}$ : eosinophils may be a prominent component of the inflammatory infiltrate in both ulcerative colitis and Crohn's disease. ${ }^{99} 100$ Eosinophilic gastroenteritis ${ }^{101} 102$ is characterised by a florid tissue and peripheral blood eosinophilia, with some histopathological similarities to chronic inflammatory bowel disease. Nevertheless, eosinophilic gastroenteritis has characteristic clinical associations: the condition lacks the characteristic histopathological changes of Crohn's disease and the crypt architectural abnormalities of ulcerative colitis are not present. ${ }^{99}$

\section{ISOLATED MUCOSAL GRANULOMAS}

Small isolated granulomas are not an unusual feature in rectal mucosal biopsy specimens. In the absence of collateral evidence to support a diagnosis of Crohn's disease a cause may not be found. Refractile crystals are always demonstrable in barium granulomas ${ }^{103}$ and it is most unusual to see evidence of sarcoidosis in rectal mucosa. ${ }^{104}$ It is likely that most of these incidental granulomas represent a tissue response to mucin, possibly as a result of crypt obstruction, inflammation, and disruption.

\section{PNEUMATOSIS CYSTOIDES INTESTINALIS}

Pneumatosis is a rare condition characterised by gas filled cysts which particularly affect the colonic submucosa. ${ }^{105}$ Clinically, the condition is more likely to simulate polyposis syndromes, ${ }^{106}$ but histologically the overlying mucosa shows features which may suggest chronic inflammatory bowel disease if biopsies are superficial. ${ }^{107}$ These include chronic inflam- 
mation, crypt distortion as a result of the underlying submucosal gas cysts, and intramucosal granulomas (fig 7). Only when biopsy specimens that include the submucosa are examined does the true nature of the disease become apparent. ${ }^{107}$

\section{Summary}

When all of the macroscopic and microscopic features of Crohn's disease and ulcerative colitis are present, the correct diagnosis is usually made without difficulty. When some of the changes are absent, the accuracy of diagnosis is reduced. This review has outlined those diseases which feature some of these pathological changes and may masquerade as idiopathic chronic inflammatory bowel disease. Some of the pathological mimics are iatrogenic while other common diseases, such as bacterial infection, ischaemia, and diverticulosis may produce confusing histological appearances. The picture is complicated by the fact that many of these pathological imitators may themselves cause or predispose to chronic inflammatory bowel disease, or may complicate chronic inflammatory bowel disease. For example, drugs and infectious agents are recognisable causes of relapse in ulcerative colitis; Crohn's disease may cause diverticulitis in patients with diverticulosis; and lymphoma may complicate ulcerative colitis. It behoves all practising histopathologists to recognise these mimics of ulcerative colitis and Crohn's disease to ensure appropriate management for patients with inflammatory pathology of the intestines.

I am most grateful to Ms Jill Maybee for photographic assistance and to Dr Bryan Warren for helpful discussions.

1 Mortensen N. Progress with the pouch-restorative proctocolectomy for ulcerative colitis. Gut 1988;29:561-5.

Beart RW. Proctocolectomy and ileoanal anastamosis. World J Surg 1988;12:160-3.

3 Price AB. Overlaps in the spectrum of non-specific inflammatory bowel disease- "colitis indeterminate". J Clin Pathol 1978;31:567-77.

4 Jass JR. The large intestine. In Morson BC, ed. Systemic pathology. 3rd ed. Vol 3: Alimentary tract. Edinburgh: Churchill Livingstone, 1987:334-46.

5 Morson BC, Dawson IMP, Day DW, Jass JR, Price AB Williams GT. Inflammatory disorders. In: Morson $\mathcal{E}$ Dawson's Gastrointestinal Pathology. 3rd ed. Oxford: Bawson's Gastrointestinal Patholo

6 Tanaka M, Riddell RH. The pathological diagnosis and differential diagnosis of Crohn's disease. Hepatoand differential diagnosis of

7 Lusk LB, Reichen J, Levine JS. Aphthous ulceration in diversion colitis. Gastroenterology 1984;87:1171-3.

8 Harig JM, Soergel KH, Komorowski RA, Wood CM Treatment of diversion colitis with short chain fatty acid irrigation. N Engl J Med 1989;320:23-38.

9 Komorowski RA. Histologic spectrum of diversion colitis. Am J Surg Pathol 1990;14:548-54.

10 Roe AM, Warren BF, Brodribb AJM, Brown C. Diversion colitis and involution of the defunctioned anorectum. $G u t$ 1990;31:A1174.

11 Glotzer DJ, Glick ME, Goldman H. Proctitis and colitis following diversion of the faecal stream. Gastroenterology 1981;80:438-41.

12 Korelitz BI, Cheskin LJ, Sohn N, Sommers SC. Proctitis after fecal diversion in Crohn's disease and its elimination with reanastamosis: implications for surgical manwith reanastamosis: implications for su

13 Murray FE, O'Brien MJ, Birkett DH, Kennedy SM, LaMont JT. Diversion colitis: pathological findings in a
resected sigmoid colon and rectum. Gastroenterology resected sigmo

$14 \mathrm{Ma} \mathrm{CK}$, Gottlieb C, Haas PA. Diversion colitis: a clinicopathological study of 21 cases. Hum Pathol 1990;21: 429-36.

15 Anonymous. Diversion colitis. [Editorial]. Lancet 1989;i:764.

16 Truelove SC, Ellis H, Webster CU. Place of doublebarrelled ileostomy in ulcerative colitis and Crohn's disease of the colon. Br Med J 1965;i:150-3.
17 Burman JH, Thompson H, Cooke W, Alexander-Williams $J$. The effects of diversion of intestinal contents on the progress of Crohn's disease of the large bowel. Gut progress of Cr.

18 Warren BF, Shepherd NA, Bartolo DCC, Bradfield JWB Histological changes of the defunctioned rectum in ulcerative colitis. J Pathol 1991;63:69A.

19 Pemberton JH, Kelly KA, Beart RW, Dozois RR, Wolf BG, Ilstrup DM. Ileal pouch-anal anastamosis for chronic ulcerative colitis. Long-term results. Ann Surg 1987;206:504-13.

20 Nicholls RJ, Pezim ME. Restorative proctocolectomy with ileal reservoir for ulcerative colitis and familial adenmatous polyposis: a comparison of three reservoir designs. Br J Surg 1985;72:470-4.

21 Hulten L, Svaninger G. Facts about the Kock continent ileostomy. Dis Colon Rectum 1984;27:553-7.

22 Shepherd NA, Jass JR, Duval I, Moskowitz RL, Nicholls RJ, Morson BC. Restorative proctocolectomy with ileal reservoir-pathological and histochemical study of reservoir-pathological and histochemical study of

23 Tytgat GNJ, Deventer SJH. Pouchitis. Int J Colorectal Di 1988;3:226-8.

24 Shepherd NA. The pelvic ileal reservoir: apocalypse later? Br Med J 1990;301:886-7.

25 Keighley MRB. Discussion in Pouchitis Workshop. Int $J$ Colorectal Dis 1989;4:213.

26 Shepherd NA. The pelvic ileal reservoir: pathology and pouchitis. Neth J Med 1990;37:S57-S64.

27 Davies DR, Brightmore T. Idiopathic and drug-induced ulceration of the small intestine. Br J Surg 1970;57:134-9.

28 Leyonmarck CE, Raf $L$. Ulceration of the small intestine due to slow-release potassium tablets. Acta Chir Scand 1985;151:273-8.

29 Lang J, Price AB, Levi AJ, Burke M, Gumpel JM Bjarnason I. Diaphragm disease: pathology of the smal intestine induced by non-steroidal anti-inflammatory drugs. J Clin Pathol 1988;41:516-26.

30 Sheers R, Williams WR. NSAIDs and gut damage. Lance 1989 ;ii: 1154.

31 Hall RI, Pelty AH, Cobden I, Lendrum R. Enteritis and colitis associated with mefanamic acid. $\mathrm{Br}$ Med 1983;287:1182.

32 Anonymous. NSAIDs and gut damage. [Editorial]. Lancet 1989;ii:600.

33 Graham CF, Gallagher K, Jones JK. Acute colitis with methyldopa. N Engl J Med 1981;304:1044-5.

34 Martin DM, Goldman JA, Gilliam J, Nasrallah SM. Goldinduced eosinophilic enterocolitis: response to ora chromolyn sodium. Gastroenterology 1981;80:1567-70.

35 Floch $M H$, Hellman $L$. The effect of 5 -fluorouracil on recta mucosa. Gastroenterology 1965;48:430-7.

36 Saunders DR, Sillery J, Rachmilewitz D, Rubin CE Tytgat GNJ. Effect of bisacodyl on the structure and function of rodent and human intestine. Gastroenterology 1977;72:849-56.

37 Leriche M, Devroede G, Sanchez G, Rossano J. Changes in the rectal mucosa induced by hypertonic enemas. Dis Colon Rectum 1978;21:227-36.

38 Levy N, Gaspar E. Rectal bleeding and indomethacin suppositories. Lancet 1975;i:577.

39 Cawthorne SJ, Gibbs NM, Marks CG. Segmental colitis: a new complication of diverticular disease. Gut 1983;24:A500.

40 Mathus-Vliegen EMH, Tytgat GNJ. Polyp-simulating mucosal prolapse syndrome in (pre)-diverticular syndrome. Endoscopy 1986;18:84-6.

41 Gore S, Shepherd NA, Wilkinson SP. Crescentic colitis: the clinical and histopathological spectrum of a distinctive endoscopic appearance in the sigmoid colon. $J$ Pathol 1991 (in press).

42 Sladen GE, Filipe MI. Is segmental colitis a complication of diverticular disease? Dis Colon Rectum 1984;27:513-14.

43 du Boulay CEH. Diverticular disease of the colon and solitary ulcer syndrome. In Whitehead R, ed. Gastrointestinal and oesophageal pathology. Edinburgh: Churchill tinal and oesophageal patholo

44 Schmidt GT, Lennard-Jones JE, Morson BC, Young AC. Crohn's disease of the colon and its distinction from diverticulitis. Gut 1968;9:7-16.

45 McCue J, Copper MJ, Rasbridge SA, Lock MR. Coexistent Crohn's disease and sigmoid diverticulosis. Postgrad Med J 1989;65:636-9.

46 Meyers AA, Alonso DR, Morson BC, Bartram CI. Pathogenesis of diverticulitis complicating granulomatous colitis. Gastroenterology 1978;74:24-31.

47 Surawicz CM, Belic L. Rectal biopsy helps to distinguish acute self-limited colitis from idiopathic inflammatory bowel disease. Gastroenterology 1984;86:104-13.

48 Nostrant TT, Kumar NB, Appelman HD. Histopathology differentiates acute self-limited colitis from ulcerative colitis. Gastroenterology 1987;92:318-28.

49 Anand BS, Malhotra V, Bhattacharya SK, et al. Rectal histology in acute bacillary dysentery. Gastroenterology $1986 ; 90: 654-60$.

50 Levine JS, Smith PD, Brugge WR. Chronic proctitis in male homosexuals due to lymphogranuloma venereum. Gastroenterology 1980;79:563-5.

51 Jass JR. The large intestine. In: Morson BC, ed. Systemic pathology. 3rd ed. Vol 3: Alimentary tract. Edinburgh: Churchill Livingstone, 1987:325-9.

52 Day DW, Mandal BK, Morson BC. The rectal biopsy appearances of salmonella colitis. Histopathology 1978;2:117-31.

53 Price AB, Jewkes J, Sanderson PJ. Acute diarrhoea: 
campylobacter colitis and the role of rectal biopsy. J Clin Pathol 1979;32:990-7.

54 Price AB, Davies DR. Pseudomembranous colitis. J Clin Pathol 1977;30:1-12.

55 Quinn TC, Goodell SE, Mkrtichian E. Chlamydia trachomatis proctitis. $N$ Engl J Med 1981;305:195-200.

56 Vantrappen G, Agg HO, Ponette E, Geboes K, Bertrand P. Yersinia enteritis and enterocolitis: gastroenterological aspects. Gastroenterology 1977;72:220-7.

57 Haggitt RC. The differential diagnosis of idiopathic inflammatory bowel disease. In: Norris HT, ed. Pathology of the colon, small intestine and anus. New York: Churchill Livingstone 1983.21-59.

58 El-Meraghi NRH, Mair NS. The histopathology of enteric infection with yersinia pseudotuberculosis. Am J Clin infection with yersinia

59 Jass JR, Shepherd NA, Maybee JD. Inflammatory disorders. In: Atlas of surgical pathology of the colon, rectum and anus. Edinburgh: Churchill Livingstone. 1989:188-9.

60 Morson BC, Dawson IMP, Day DW, Jass JR, Price AB, Williams GT. Inflammatory disorders. In: Morson $\mathcal{E}$ Dawson's Gastrointestinal Pathology. 3rd ed. Oxford: Blackwell Scientic, 1990:275-6.

61 Haggitt RC. The differential diagnosis of idiopathic inflammatory bowel disease. In: Norris HT, ed. Pathology of the colon small intestine and anus. New York: Churchill Livingstone, 1983:21-59.

62 Cooper HS, Raffensperger ED, Jonas L, Fitts WT. Cytomegalovirus inclusions in patients with ulcerative Cytomegalovirus inclusions in patients with ulcerative colitis and toxic dilatation requirin

63 Read NW, Krejs GJ, Read MG, Santa Ana CA, Morawski SG, Fordtran JS. Chronic diarrhoea of unknown origin. Gastroenterology 1980;78:264-71.

64 Kingham JGC, Levison DA, Ball JA, Dawson AM. Microscopic colitis-a cause of chronic watery diarrhoea. Br J Med 1982;285:1601-4.

65 Elliott PR, Williams CB, Lennard-Jones JE, et al. Colonoscopic diagnosis of minimal change colitis in patients with a normal sigmoidoscopy and normal air-contrast barium enema. Lancet 1982;i:650-1.

66 Sanderson IR, Boyle S, Williams CB, Walker-Smith JA. Histological abnormalities in biopsies from macroscopically normal colonoscopies. Arch Dis Child scopically norm

67 Lazenby A, Yardley J, Giardiello F, Jessurun J, Bayless T. Lymphocytic ("microscopic") colitis. A comparative histopathologic study with particular reference to collagenous colitis. Hum Pathol 1989;20:18-28.

68 Giardiello FM, Lazenby AJ, Bayless TM, et al. Lymphocytic (microscopical) colitis. Clinicopathologic study of 18 patients and comparison to collagenous colitis. Dig Dis $S c i$ 1989;34:1730-8.

69 Whitehead R. The pathology of intestinal ischaemia. Clin Gastroenterol 1972;1:613-37.

70 Morson BC, Dawson IMP, Day DW, Jass JR, Price AB, Williams GT. Vascular disorders. In: Morson E Dawson's gastrointestinal pathology. 3rd ed. Oxford: Blackwell Scientific, 1990:551-9.

71 Smith GE, Kime LR, Pitcher JL. The colitis of Behcet's disease: a separate entity? Am J Dig Dis 1973;18:987-99.

72 O'Connell DJ, Courtney JV, Riddell RH. Colitis of Behcet's syndrome: radiologic and pathologic features. Gastrointest Radiol 1980;5:173-9.

73 Baba S, Maruta $M$, Ando $K$, Teramoto $T$, Endo I. Intestinal Behcet's disease; report of five cases. Dis Colon Rectum 1976;9:428-40.

74 Lee RG. The colitis of Behcet's syndrome. Am J Surg Pathol 1986;10:888-93.

75 Morson BC, Dawson IMP, Day DW, Jass JR, Price AB, Williams GT. Inflammatory disorders. In: Morson $\mathcal{E}$ Wawson's gastrointestinal pathology. 3rd ed. Oxford: Dawson's gastrointestinal patholog

76 Morson BC, Dawson IMP, Day DW, Jass JR, Price AB, Williams GT. Non-epithelial tumours. In: Morson $\mathcal{E}$ Dawson's gastrointestinal pathology. 3rd ed. Oxford: Blackwell Scientific, 1990:376-7.

77 Shepherd NA, Blackshaw AJ, Hall PA, et al. Malignant lymphoma with eosinophilia of the gastrointestinal tract. Histopathology 1987;11:115-30.

78 Richards MA. Lymphoma of the colon and rectum. Postgrad Med J 1986;62:615-20.

79 Friedman HB, Silver GM, Brown $\mathrm{CH}$. Lymphoma of the colon simulating ulcerative colitis. Am J Dig Dis 1968; 13:910-17.
80 Myerson P, Myerson D, Miller D, DeLuca VA, Lawson JP. Lymphosarcoma of the bowel masquerading as JP. Lymphosarcoma of the bowel masqueradi
ulcerative colitis. Dis Colon Rectum 1974;17:710-5.

81 Sagar S, Selby P, Sloane J, McElwain TJ. Colorectal lymphoma simulating inflammatory colitis and diagnosed by immunohistochemistry. Postgrad Med J 1986;62:51-3.

82 Shepherd NA, Hall PA, Williams GT, et al. Primary malignant lymphoma of the large intestine complicating chronic inflammatory bowel disease. Histopathology 1989 ; 15:325-37.

83 Epstein RJ, McDonald GB, Sale GE, Shulman HM, Thomas ED. The diagnostic accuracy of the rectal biopsy in acute graft-versus-host disease: a prospective study of in acute graft-versus-host disease: a prospective study

84 Thorning D, Howard JD. Epithelial denudation in the gastrointestinal tract of two bone marrow transplant recipients. Hum Pathol 1986;17:560-6.

85 Sale GE, McDonald GB, Shulman HM, Thomas ED. Gastrointestinal graft-versus-host disease in man. A clinicopathological study of rectal biopsy. Am J Surg Pathol 1979;3:291-9.

86 Kotler DP, Gaetz HP, Lange M, Klein EB, Holt PR. Enteropathy associated with the acquired immunodeficiency syndrome. Ann Intern Med 1984;101:421-8.

87 Kotler DP, Weaver SC, Terzakis JA. Ultrastructural features of epithelial cell destruction in rectal crypts of patients with AIDS. Am J Surg Pathol 1986;10:531-8.

88 Nelson JA, Wiley CA, Reynolds-Kohler C, Reese CA, Margaretten W, Levy JA. Human immunodeficiency virus detected in bowel epithelium from patients with gastrointestinal symptoms. Lancet 1988;i:259-62.

89 Werlin SL, Chusid MJ, Caya J, Oechler HW. Colitis in chronic granulomatous disease. Gastroenterology 1982;82: 328-31.

90 Ament ME, Ochs HD. Gastrointestinal manifestations of chronic granulomatous disease. $N$ Engl $J$ Med 1973;288:382-7.

91 Yogman MW, Touloukian RJ, Gallagher R. Intestinal granulomatosis in chronic granulomatous disease and in Crohn's disease. N Engl J Med 1974;290:228.

92 Ament ME, Rubin CE. Relation of giardiasis to abnormal intestinal structure and function in gastrointestinal immunodeficiency syndromes. Gastroenterology 1972;62: immunoder.

93 Hermans PE, Huizenga KA, Hoffman HN, Brown AL, Markowitz H. Dysgammaglobulinaemia associated with nodular hyperplasia of the small intestine. $\mathrm{Am} \mathrm{J} \mathrm{Med}$ 1966;40:78-89.

94 Gray BK, Lockhart-Mummery HE, Morson BC. Crohn's disease of the anal region. Gut 1965;6:515-24

95 Davis DR, Dockerty MB, Mayo CW. The myenteric plexus in regional enteritis: a study of ganglion cells in the ileum in 24 cases. Surg Gynecol Obstet 1955:101:208-16.

96 Whitehead R. Pathology of Crohn's disease. In: Kirsner JB, Shorter RG, eds. Inflammatory bowel disease. 2nd ed. Philadelphia: Lea \& Febiger, 1980:296-307.

97 Carney JA, Go VLW, Sizemore GW, Hayle AB. Alimentary tract ganglioneuromatosis. $N$ Engl J Med 1976; 295:1287-91.

98 Shepherd NA, Jass JR. Neuromuscular and vascular hamartoma: is it Crohn's disease? Gut 1987;28:1663-8.

99 Blackshaw AJ, Levison DA. Eosinophilic infiltrates in the gastrointestinal tract. J Clin Pathol 1986;39:1-7.

100 Heatley RV, James PD. Eosinophils in the rectal mucosa. A simple method of predicting the outcome of ulcerative colitis. Gut 1979;20:787-91.

101 Klein NC, Hargrove RL, Sleisinger MH, Jeffries GH. Eosinophilic gastroenteritis. Medicine 1970;49:299-319.

102 Johnstone JM, Morson BC. Eosinophilic gastroenteritis. Histopathology 1978;2:335-48.

103 Levicon DA, Crocker PR Smith A, Blackshaw AJ, Bartram CI. Varied light and scanning electron microscopic appearances of barium sulphate in smears and histological sections. J Clin Pathol 1984;37:481-7.

104 Tobi M, Kobrin I, Ariel I. Rectal involvement in sarcoidosis. Dis Colon Rectum 1982;25:491-3.

105 Galandiuk S, Fazio VW. Pneumatosis cystoides intestinalis. A review of the literature. Dis Colon Rectum 1986; 29:358-63.

106 Calne RY. Gas cysts of the large bowel simulating multiple polyposis. Br J Surg 1959;47:212-15.

107 Pieterse AS, Leong ASY, Rowland R. The mucosal changes and pathogenesis of pneumatosis cystoides intestinalis. Hum Pathol 1986;16:683-8. 